\title{
CFD SIMULATION OF THE HEAT TRANSFER PROCESS IN A CHEVRON PLATE HEAT EXCHANGER USING THE SST TURBULENCE MODEL
}

\author{
JAN SkočIlaS $^{a, *}$, IEvgen PAlazIUK $^{b}$ \\ ${ }^{a}$ Czech Technical University in Prague, Faculty of Mechanical Engineering, Department of Process Engineering, \\ Technicka 4, 16607 Prague 6, Czech Republic \\ ${ }^{b}$ National Aerospace University, "Kharkiv Aviation Institute" named after N. Ye. Zhukovsky, Faculty of \\ Airplane Building, Department of Aircraft Manufacturing Technology, Chkalova 17, 61070, Kharkiv, Ukraine \\ * corresponding author: jan.skocilas@fs.cvut.cz
}

\begin{abstract}
This paper deals with a computational fluid dynamics (CFD) simulation of the heat transfer process during turbulent hot water flow between two chevron plates in a plate heat exchanger. A three-dimensional model with the simplified geometry of two cross-corrugated channels provided by chevron plates, taking into account the inlet and outlet ports, has been designed for the numerical study. The numerical model was based on the shear-stress transport (SST) $k$ - $\omega$ model. The basic characteristics of the heat exchanger, as values of heat transfer coefficient and pressure drop, have been investigated. A comparative analysis of analytical calculation results, based on experimental data obtained from literature, and of the results obtained by numerical simulation, has been carried out. The coefficients and the exponents in the design equations for the considered plates have been arranged by using simulation results. The influence on the main flow parameters of the corrugation inclination angle relative to the flow direction has been taken into account. An analysis of the temperature distribution across the plates has been carried out, and it has shown the presence of zones with higher heat losses and low fluid flow intensity.
\end{abstract}

KEYwordS: CFD; simulation; ANSYS CFX; ANSYS CFD-Post; heat transfer; plate heat exchanger; chevron corrugated plates; pressure drop; heat transfer coefficient.

\section{INTRODUCTION}

Heat exchangers play an important role in heat power engineering, as well as in food, beverage, chemical, pharmaceutical, oil refining and other industries. Several main types of indirect heat exchangers are available: plate, shell and tube, spiral etc. In most cases the plate type is the most efficient heat exchanger because it offers the best solution to thermal problems, having the widest pressure and temperature limits within the constraints of current equipment. Plate heat exchangers have many benefits because they are more thermally efficient, occupy less space, are lighter and do not need to be cleaned as often as shell and tube heat exchangers. Corrugated plates merged together create a cavity which enhances the turbulent flow in the liquid in order to maximize heat transfer in the exchanger. A high degree of turbulence can be obtained at low flow rates and a high heat transfer coefficient can then be reached. In order to increase the heat transfer in plate type heat exchangers using a passive method, rectangular fins are located on the plates, so that the flow path of the fluid and the surface area of the plates are increased [1]. An optimal performance is achieved for less obtuse (i.e., sharper) corrugations as the channel plates are coming closer to each other, while the plate heat exchanger performance can be improved for lower values of channel aspect ratio (i.e., wider channels) and for higher values of the corrugation angle as the Reynolds number increases [2]. With the constraints of fixed plate surface geometry and constant pumping power, the heat transfer can be enhanced up to 2.8 times compared to that in a flat-plate channel [3. Comparing the tested 60 degree chevron plate with 30 degree and 45 degree plates, the result shows a higher Nusselt number in the case of the 60 degree, at a wide Reynolds number range 4 . The heat transfer coefficient and the pressure drop increase proportionally to the mass flow rate and inversely to the chevron angle [5].

A calculation of various heat exchanger modes is required for a wide range of tasks, which include: determination of thermal power and coolant flow rate in the absence of flow meters, prediction of required physical parameters and flow velocities of coolant, formulation of rationale for the choice of pipeline systems equipment, diagnostics of the heating surfaces, etc. To achieve the objectives of efficiency improvement of heat exchangers, it is necessary to apply modern approaches to their design. The main requirements which have to be met by an engineer specializing in analysing, in design or in optimizing existing heat exchange equipment are to reduce the time required to solve the assigned problem and to minimize the problem-solving costs. In the case of lack of required equipment or when carrying out experiments is too 
expensive, a quick and cheap alternative is to make a simulation of the considered processes.

A key advantage of CFD is that it is a very compelling, non-intrusive, virtual modelling technique with powerful visualization options, which allows engineers to evaluate the performance of a wide range of technical system configurations on a computer without the time, expenses, and disruptions required to make actual changes. CFD simulation largely saves cost and turnaround time and makes it possible to obtain reliable results, and this method is therefore widely used in the process of design and upgrade of plate heat exchangers. The quality of the solutions obtained from CFD simulations is largely within the acceptable range, which proves that this method is an effective tool for predicting the behavior and performance of a wide variety of heat exchangers [6]. The computations enable us to point out the regions on the plates where insufficient flow can result in problems with their cleaning [7. A simulation allows us to clearly demonstrate that the phenomenon of non-uniform distribution of the fluid is a major factor affecting the performance of plate heat exchangers, which can be weakened by rolling guide area in the corrugated board [8]. Investigations by CFD can be helpful for determining the hydrodynamic characteristics and the flow distribution in two cross-corrugated channels [9]. CFD results help to identify features of the flow field in detail, and they can explain the distribution of convection coefficients [10. The temperature distribution obtained by simulation can be helpful for selecting the plate material [11. Thanks to CFD results you can get detailed information about the fluid velocities near the wall in thermal boundary layer, and hence these information enhance the accuracy of the calculation of the heat transfer coefficient and pressure drop values 12 . 2D calculations show the influence of the corrugation shape on the performance of plate heat exchangers, but 3D calculations are necessary in order to assess the importance of the corrugation orientation [13].

This study deals with numerical simulation of the heat transfer process during turbulent hot water flow between two chevron corrugated plates in a plate heat exchanger. In the article a simplification of the heat exchanger geometry is used and an effective methodology for the design and calculation of heat exchangers is one of the aims. The main objective of the paper is to determine performance characteristics of the heat exchanger e.g. the values of the heat transfer coefficient and the pressure drop by carrying out investigations of the main flow parameters for different geometrical configurations.

\section{THEORY}

The methods focused on the intensification of heat transfer are usually associated with an increase in hydraulic resistance. Improving the heat transfer efficiency leads to an increase in hydraulic resistance.

\begin{tabular}{cccccc}
\hline$C_{1}$ & $y$ & $C_{2}$ & $n$ & $m$ & $x$ \\
\hline 1.22 & 0.252 & 0.14 & 0.65 & 0.4 & 0.1 \\
\hline
\end{tabular}

TABle 1. Coefficients and exponents used in the calculations [15, 16].

The important task is therefore to find transfer surface geometries which have the greatest value of heat transfer coefficient at the lowest possible value of hydraulic resistance (i.e., of the power required to pump coolant).

Pressure drop is one of the main heat exchanger characteristics, and it is in direct relationship to the size of the plate heat exchanger. The pressure drop value determines the pump power which is required for pumping the working fluid through the channels of the heat exchange apparatus. If it is possible to increase the allowable pressure drop, and incidentally accept higher pumping costs, then the heat exchanger will be smaller and less expensive. The performance of the many different corrugation forms can vary considerably, but the pressure loss in a plate heat exchanger can always be calculated from a fanning friction factor type of equation [14]:

$$
\Delta P=\frac{2 f L G^{2}}{\rho d_{e}} .
$$

The general equation for predicting the friction factor coefficient has the following form:

$$
f=\frac{C_{1}}{R e^{y}}
$$

where coefficient $C_{1}$ and exponent $y$ are the performance characteristics of the heat exchanger, which depend on individual geometry features of the plates. Exponent $y$ generally varies from 0.1 to 0.4 [15, 16]. The heat transfer performance of plate-type units can be calculated from typical dimensionless heat transfer equations, with the appropriate constants and exponents for each specific type of heat exchanger:

$$
N u=C_{2} \operatorname{Re}^{n} \operatorname{Pr}^{m}\left(\frac{\eta}{\eta_{w}}\right)^{x}
$$

where $N u=\alpha d_{e} / \lambda, d_{e}=4 S / P=2 b, R e=\nu d_{e} \rho / \mu$ and $\operatorname{Pr}=c_{p} / \lambda$.

The typical values of constant $C_{2}$ and exponents $n, m, x$ depend on individual characteristics of the plate surface geometry and of the coolant flow regime. In different cases they have the following values: $C_{2}=$ $0.065-0.60, n=0.3-0.75, m=0.3-0.45, x=0.05-0.2$ [15, 16].

The coefficients and exponents used in the analytical calculations for the considered geometry of heat exchanger plates, according to their dimensions, are shown in Table 1 

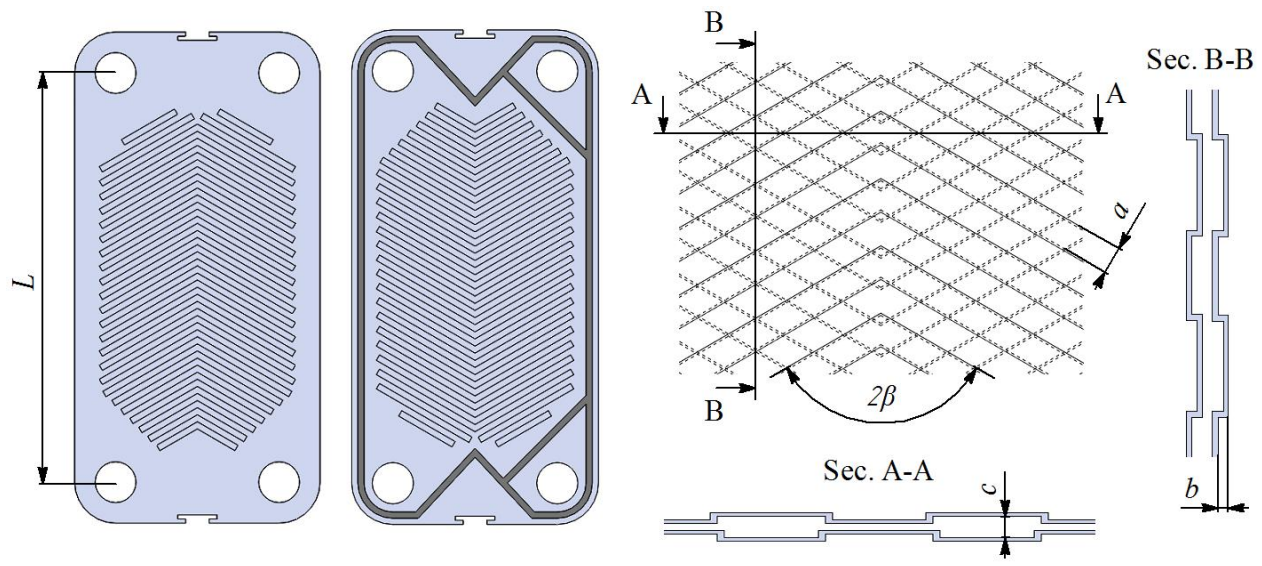

Figure 1. Basic geometrical parameters and dimensions of the heat exchanger plates.

\begin{tabular}{ccccccc}
\hline$L$ & $W$ & $a$ & $b$ & $c$ & $d$ & $\beta$ \\
\hline $1000 \mathrm{~mm}$ & $400 \mathrm{~mm}$ & $15 \mathrm{~mm}$ & $2 \mathrm{~mm}$ & $6 \mathrm{~mm}$ & $1 \mathrm{~mm}$ & $30^{\circ} ; 45^{\circ} ; 60^{\circ}$ \\
\hline
\end{tabular}

TABLE 2. Dimension values of the considered heat exchanger plates.
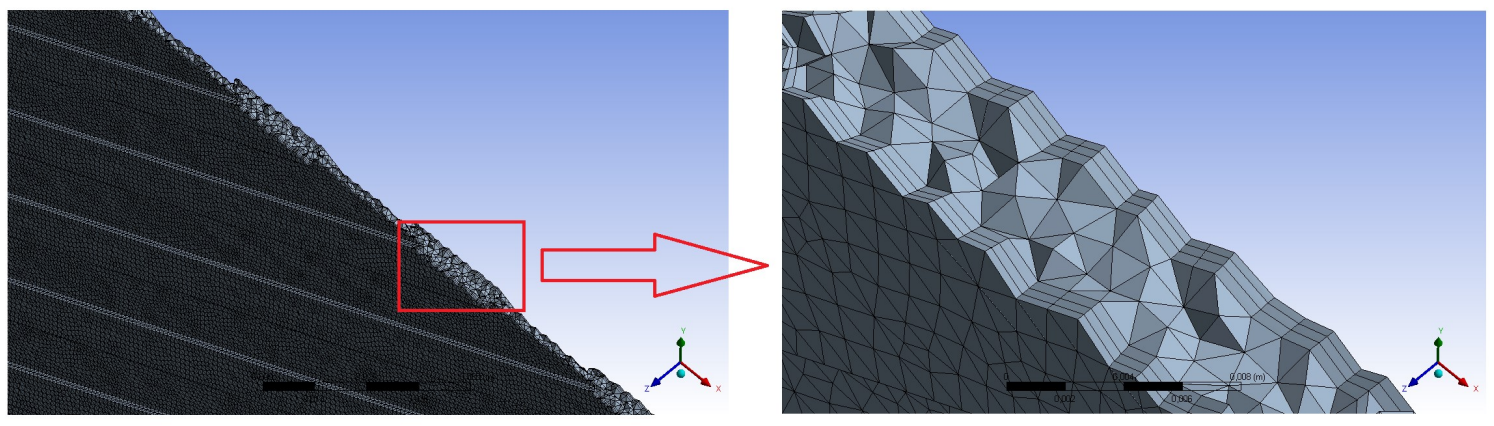

Figure 2. Finite element mesh.

\section{Numerical MOdEL GeOMETRY, GRID AND PRE-PROCESSOR SET-UP}

The basic geometry of the investigated model was created in the solid modelling computer-aided design (CAD) software SolidWorks 2013. For study purposes, a simplified geometry of plates with orthogonal chevron shape corrugations (without rounding), available among the Internet resources of the GrabCAD engineering portal [17, was considered. We used identical plates with mutually reverse orientation of the corrugations on adjacent plates. The basic geometrical parameters and dimensions of the plates are shown in Figure 1. The assembly of single plates into the package is performed by means of separating rubber gaskets. The influence of the corrugation inclination angle relative to flow direction on the main flow parameters was taken into account. In order to investigate the influence of the corrugations on the flow parameters and the intensification of heat transfer processes, flat plates were also considered. To simplify the numerical model and reduce computational costs, only the fluid flow domain was considered. The dimension values of the considered heat exchanger plates are shown in Table 2
The finite element mesh was created by means of ANSYS Meshing software, as this technology provides a means to balance all mesh requirements and obtain the right mesh for each simulation in the most automated way possible [18. When creating the finite element mesh, tetrahedral elements were used (Figure 2). For a more accurate modeling of the near-wall flow in the boundary layer near the contact surfaces of coolant and plates, special layers of prismatic elements were constructed. It is worth noting that the sizes of these elements were set according to the requirements for the value of the non-dimensional distance from the wall to the first mesh node $y^{+}$for the turbulence model used. The average total number of elements for the different cases was amounted to $6 \cdot 10^{6}$.

Because the regime of coolant flow in heat exchangers is generally turbulent, the choice of an appropriate turbulence model is of great importance. In some cases the turbulence model can have a huge effect on the results which are obtained from CFD. The $k-\varepsilon$ turbulence model has been most widely employed for heat exchanger design optimization using CFD software [6]. The simulations generally yield results in good agreement with the experimental studies, ranging from $2 \%$ 

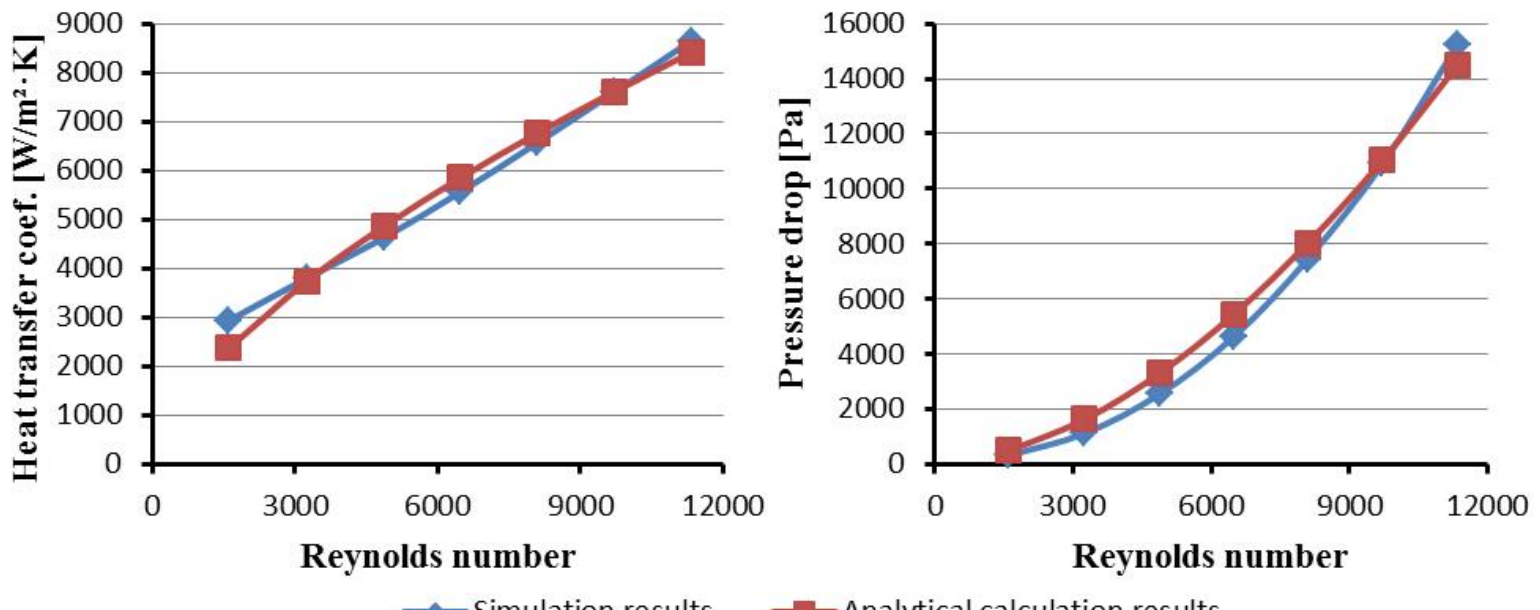

FiguRE 3. Change in heat transfer coefficient and pressure drop with increasing Reynolds numbers for plates with $\beta=60^{\circ}$.
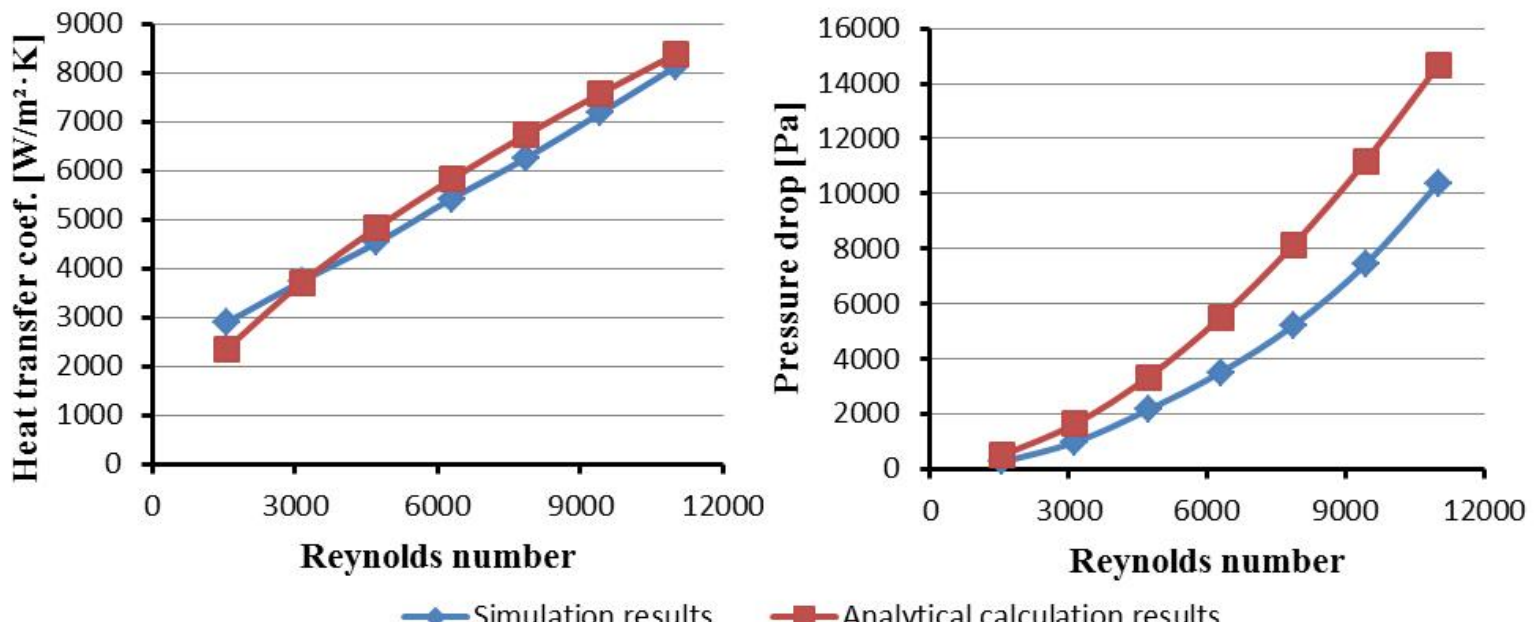

FiguRE 4. Change in heat transfer coefficient and pressure drop with increasing Reynolds numbers for plates with $\beta=45^{\circ}$.

to $10 \%$, but in some exceptional cases they vary up to $36 \%$. The difference turbulence model was used in the numerical model design [19]. The simulation results show that the $k-\omega$ and $k-\varepsilon$ turbulence models give an overestimation of the Nusselt number maximum value (up to $20 \%$ ), whereas the calculation results obtained using the SST model differ from experimental data by no more than $5 \%$. The results of a numerical simulation of the heat transfer process during shock waves damping in an enclosed chamber after the detonation of a gas mixture were also taken into account [20]. The use of the SST turbulence model for simulation of the heat transfer between hot combustion products and solid body, located in the chamber, has shown a good accuracy during the comparison of simulation results and experimental data. On this basis, within the framework of this task, the SST turbulence model was used.

The numerical solution for all considered cases was carried out in ANSYS CFX v15.0, which contains the wide array of advanced models and technology of a leading CFD software package [21]. With ANSYS CFX we are able to predict the impact of fluid behaviour on the basic characteristics of the plate heat exchanger. A varying intensity of the coolant flow was set by changing the mass flow rate value $\dot{m}$ at the inlet, which directly affects the flow velocity and, as a consequence, the value of the Reynolds number. During the simulation the mass flow rate varied from 0.2 to $1.4 \mathrm{~kg} / \mathrm{s}$. In all cases the inlet temperature was equal to $60^{\circ} \mathrm{C}$; the pressure to 1 bar; and the value of turbulence intensity to $5 \%$. The boundary condition at the area of liquid stream which is in contact with the separating gasket was set as adiabatic wall. Negative heat flux equal to $-8000 \mathrm{~W} / \mathrm{m}^{2}$ was applied to the flow area, which is the contact surface of coolant and of the plates through which heat transfer occurs. The given value of heat flux allows reaching a temperature difference at the inlet and outlet ports of about $10-15{ }^{\circ} \mathrm{C}$ at low Reynolds numbers. The use of 

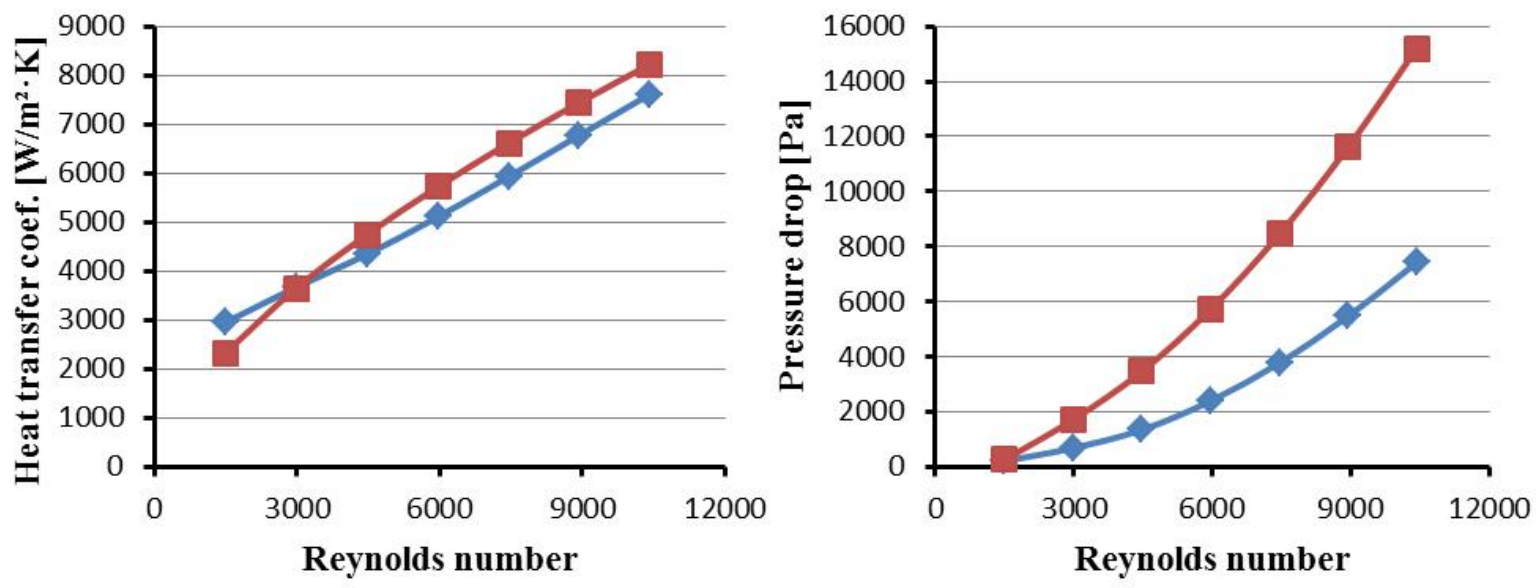

$\multimap$ Simulation results

-Analytical calculation results

FiguRE 5. Change in heat transfer coefficient and pressure drop with increasing Reynolds numbers for planes with $\beta=30^{\circ}$.

\begin{tabular}{ccccccccc}
\hline$\beta\left[^{\circ}\right]$ & $C_{1}$ & $y$ & $C_{2}$ & \multicolumn{1}{c}{$n$} & \multicolumn{1}{c}{$m$} & $x$ & $\delta(\alpha)[\%]$ & $\delta(\Delta P)[\%]$ \\
\hline 60 & 1.19 & 0.254 & 0.14 & 0.65 & 0.4 & 0.1 & 4.9 & 12.7 \\
45 & 1.06 & 0.28 & 0.14 & 0.645 & 0.395 & 0.1 & 2.4 & 6.8 \\
30 & 0.88 & 0.3 & 0.14 & 0.64 & 0.39 & 0.1 & 2.5 & 13.8 \\
\hline
\end{tabular}

TABLE 3. Recalculated values of coefficients and exponents for different angles $\beta$.

this boundary condition allowed simulating the process of heat transfer and significantly simplified our numerical model.

\section{Simulation Results AND their DISCUSSION}

To benefit from the prediction requires post-processing providing complete insight into the results of the fluid dynamics simulation. An analysis of our simulation results was carried out using the ANSYS CFD-Post v15.0 software. It is a powerful post-processor for ANSYS fluid dynamics products, which delivers everything needed to visualize and analyze the obtained results [22].

In order to evaluate the adequacy of the used numerical model, a comparative analysis of the simulation results and of the analytical calculation results was carried out. We compared the values of heat transfer coefficient and pressure drop. In Figures 35 , charts of heat transfer coefficient and pressure drop change with increasing Reynolds numbers for plates with different values of the corrugation inclination angle $\beta$ are shown.

In the case of using plates with an angle $\beta=60^{\circ}$ at high Reynolds numbers, the maximum deviation in determining the heat transfer coefficient during the simulation compared to the results of analytical calculations is $5.1 \%$, and the deviation when determining the pressure drop is $14 \%$. If the angle $\beta$ decreases, the difference between the considered parameter values increases, and in the case of $\beta=30^{\circ}$ the deviation of the determined heat transfer coefficient is $11.5 \%$, and of the determined pressure drop is $59.1 \%$.

In the analytical calculations for different $\beta$ angles, we used the constant values of coefficients and exponents which are shown in Table 1 As can be seen in the graphs, these values almost fully correspond to the case when plates with $\beta=60^{\circ}$ are used (Figure 3). In fact, a decrease of the corrugation inclination angle $\beta$ leads to a reduction of hydraulic resistance and consequently reduces the efficiency of heat transfer [1, 3], which explains the deviation increase for the considered parameters between analytical calculation results and the data obtained through numerical simulation (Figures 4 and 5 .

When using the simulation results, we can obtain more accurate values of the coefficients and exponents for different corrugation inclination angles $\beta$ of the considered plates by recalculating the values of the fanning friction factor coefficient and of the Nusselt number (Equations 2 and 3). The results of the recalculation are shown in Table 3 . Using the obtained coefficients and exponents can lead to a significant reduction of the maximum deviation $\delta$ of the simulation results compared to the analytical calculation results when determining the heat transfer coefficient change $\delta(\alpha)$ and the pressure drop change $\delta(\Delta P)$.

Figure 6] below, shows a picture of the hot water flow temperature distribution along the plate for different values of the corrugation inclination angle relative to flow direction. In all cases, initial and boundary conditions were identical. The inlet mass flow rate value $\dot{m}$ was equal to $1.2 \mathrm{~kg} / \mathrm{s}$. An increase 

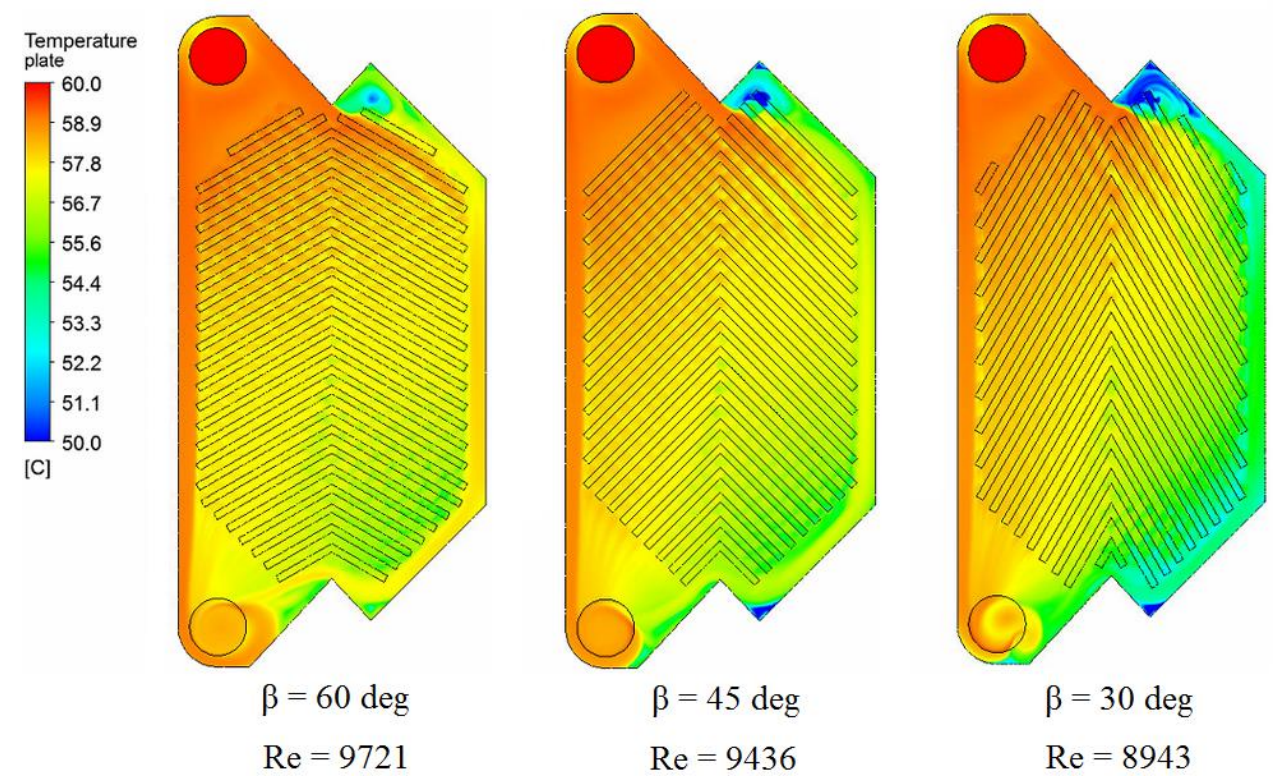

Figure 6. Picture of flow temperature distribution along the plates with different $\beta$.
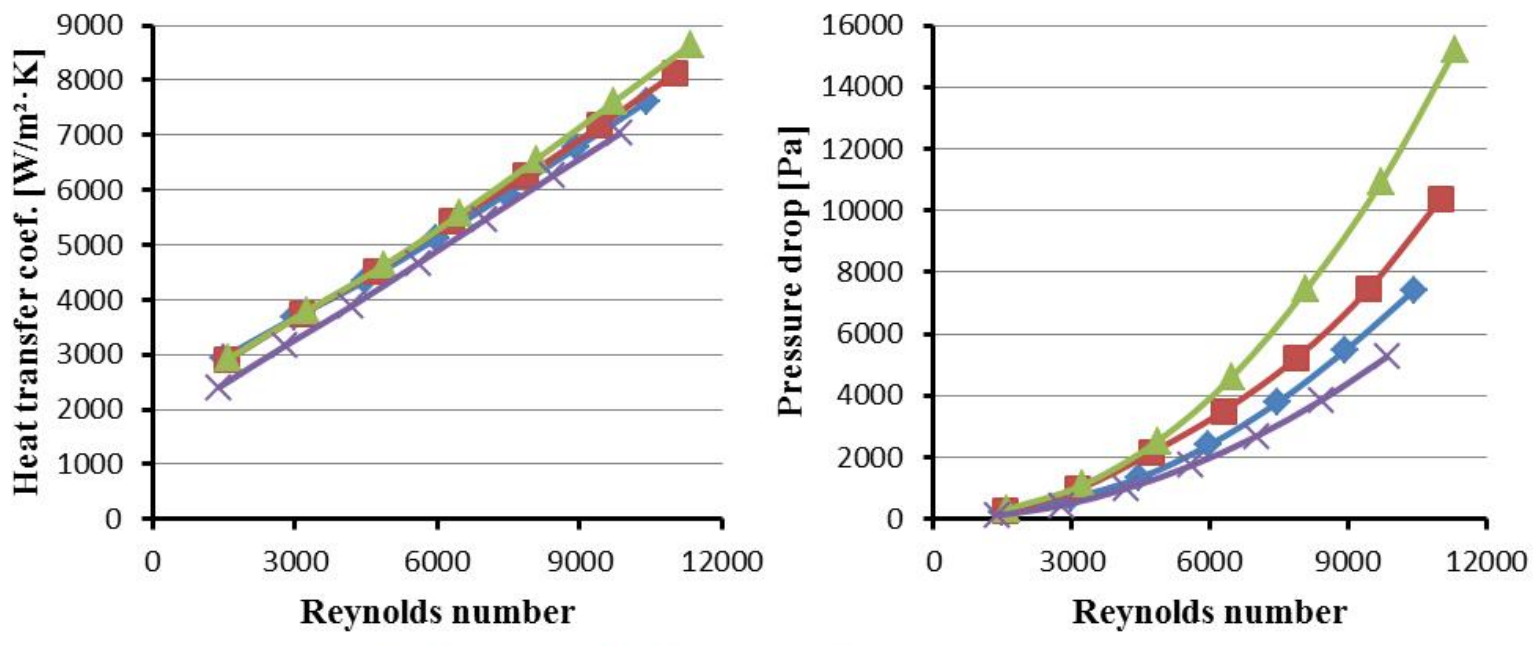

$\multimap \beta=30 \mathrm{deg}-\beta=45 \mathrm{deg} \multimap \beta=60 \mathrm{deg} \varkappa$ flat plates

FiguRE 7. Change in heat transfer coefficient and pressure drop with increasing Reynolds number for plates with different $\beta$ and for the flat plates.

in the angle $\beta$ leads to an increase of the Reynolds number and hence to a greater flow turbulence, which in turn affects the heat transfer process. When the coolant flows downstream, the flow temperature gradually decreases due to the convective heat transfer process. The temperature distributions of the fluids are similar in all the considered cases: the maximum temperature appears around the upper inlet port and the lowest temperature appears in some areas with the lowest flow intensity. From Figure 6 it can clearly be seen that with a decreasing corrugation inclination angle there is an increase in the flow zones with a lower temperature. The presence of these zones is caused by an increase in heat losses in some areas due to a reduction of the local heat transfer coefficient. This disadvantage can be eliminated by changing the geometry of the plate, which excludes the existence of shadow zones. Near the sides of the plates without corrugations, there are smooth flow passages that reduce the heat transfer and the pressure drop. These areas of flow represent about $20 \%$ of the total mass flow through the considered channels between the used plates.

As mentioned above, the increase of the hydraulic resistance promotes an intensification of the heat transfer processes. However, the value of the pressure drop increases, which is clearly demonstrated in Figure 7. In order to demonstrate the advantages of using chevron corrugations, the case when smooth plates are used was considered. The obtained results show that chevron plate surface corrugations promote higher heat transfer coefficients, but there is a higher 
pressure drop penalty as well. In the considered range of the Reynolds number the used geometry of corrugations at values of angle $\beta=60^{\circ}$ enables a gain in heat transfer coefficient of 1.23 times compared to a flat plate, while the pressure drop is 2.89 times higher at the maximum considered value of mass flow rate $\dot{m}=1.4 \mathrm{~kg} / \mathrm{s}$. The low values of heat transfer coefficient and pressure drop can be explained by geometric features of the used plates: the orthogonal shape of the corrugations, the presence of smooth channels near the plate sides, the presence of a gap between plates, and the presence of shadow zones with a low intensity of flow.

\section{Conclusions}

The proposed model of turbulent water coolant flow between two chevron corrugated plates in a plate heat exchanger can provide us with complex information about basic flow parameters and features of the heat transfer process. The adequacy of the numerical model which was used was evaluated by a comparative analysis of simulation results and analytical calculation results based on experimental data. The maximum deviation of the obtained results when determining the heat transfer coefficient is $4.9 \%$ and it is $13.8 \%$ when determining the pressure drop.

The general values of the parameters in Equation 3 for the evaluation of the Nusselt number are in good agreement with the simulated data. However, the calculation of pressure drops strongly depends on the inclination angle and the parameters of Equation 2 significatly vary with the Reynolds number and cannot be applied as constants for all inclination angles.

This numerical model can be directly used to calculate the flow parameters depending on the heat exchanger various characteristics. The model can also be used to predict the basic performance characteristics of the plate heat exchanger depending on a variety of plate geometrical configurations: its overall dimensions, forms of corrugations, corrugation inclination angles, location of inlet and outlet pipes, etc. A great advantage of the used numerical model is that when there is a change in the geometry, the reconstructing of the finite volume grid occurs automatically, which gives us significant time savings.

The simulation results show the advantages of using chevron corrugations compared to using smooth plates. Chevron plate surface corrugations promote higher heat transfer coefficients. However, there are higher pressure drop values due to an increase in the hydraulic resistance. Increasing the corrugation inclination angle leads to an increase in the heat transfer coefficient as well as an increase of the pressure drop. These results can help solve the problem of finding optimal heat transfer surfaces geometries, which have the greatest value of heat transfer coefficient at the lowest possible value of hydraulic resistance.

However, in spite of the advantages of this model, there remain several directions for further improve- ment. During the described investigations, we used constant physical properties of water coolant, so our numerical model can be improved by setting properties as functions of temperature. We should also consider the process of heat transfer from the hot water flow to the cold liquid through the physical separating wall, which would correspond to the real conditions, but would require more computing power. Moreover, the model results are not in good agreement with previously published data, which is obviously due to the following geometric features of the used plates: orthogonal shape of corrugations, presence of smooth channels near the plate sides, presence of a gap between plates, and presence of shadow zones with low intensity of flow.

\section{LIST OF SYMBOLS}

a Length of surface corrugation in a cross section [mm]

$b$ Corrugation depth [mm]

$c$ Maximum width of channel flow [mm]

$d \quad$ Plate thickness [mm]

$c_{p}$ Specific heat $\left[\mathrm{J} \mathrm{kg}^{-1} \mathrm{~K}^{-1}\right]$

$d_{e}$ Hydraulic diameter $[\mathrm{m}]$

$f \quad$ Fanning friction factor $[-]$

$G$ Mass velocity $\left[\mathrm{kg} \mathrm{m}^{-2} \mathrm{~s}^{-1}\right]$

$L \quad$ Plate length between ports [m]

$\dot{m}$ Mass flow rate $\left[\mathrm{kg} \mathrm{s}^{-1}\right]$

$N u$ Nusselt number [-]

$P \quad$ Wetted perimeter of channel flow [m]

$\operatorname{Pr}$ Prandtl number $[-]$

Re Reynolds number [-]

$S$ Cross sectional area of channel flow $\left[\mathrm{m}^{2}\right]$

$T$ Temperature $[\mathrm{K}]$

$v$ Velocity $\left[\mathrm{m} \mathrm{s}^{-1}\right]$

$W \quad$ Plate width between ports [m]

$y^{+}$Dimensionless wall distance $[-]$

$\Delta P$ Pressure drop $[\mathrm{Pa}]$

$\alpha$ Heat transfer coefficient $\left[\mathrm{W} \mathrm{m}^{-2} \mathrm{~K}^{-1}\right]$

$\beta$ Corrugation inclination angle relative to flow direction [०]

$\eta \quad$ Bulk dynamic viscosity $[\mathrm{Pas}]$

$\eta_{w} \quad$ Wall dynamic viscosity $[\mathrm{Pas}]$

$\lambda$ Thermal conductivity $\left[\mathrm{W} \mathrm{m}^{-1} \mathrm{~K}^{-1}\right]$

$\mu$ Dynamic viscosity [Pas]

$\rho$ Density $\left[\mathrm{kg} \mathrm{m}^{-3}\right]$

\section{REFERENCES}

[1] Durmus A., Benli H., Kurtbas I., Gul H.: Investigation of heat transfer and pressure drop in plate heat exchangers having different surface profiles. International Journal of Heat and Mass Transfer, 52, 2009, pp. 1451 - 1457. ISSN 0017-9310.

[2] Kanaris A.G., Mouza A.A., Paras S.V.: Optimal design of a plate heat exchanger with undulated surfaces. International Journal of Thermal Sciences, 48, 2009, pp. 1184 - 1195. ISSN 1290-0729. 
[3] Muley A., Manglik R.M.: Experimental Study of Turbulent Flow Heat Transfer and Pressure Drop in a Plate Heat Exchanger With Chevron Plates. Journal of Heat Transfer, 121, 1999, pp. 110 - 117. ISSN 0022-1481.

[4] Naik V.R., Matawala V.K.: Experimental Investigation of single phase Chevron Type Gasket Plate Heat Exchanger. International Journal of Engineering and Advanced Technology, 2, 2013, pp. 362 - 369. ISSN 2249-8958.

[5] Muthuraman S.: The Characteristics of Brazed Plate Heat Exchangers with Different Chevron Angles. Global Journal of researches in engineering, 11, 2011, pp. 10 26. ISSN 2249-4596.

[6] Aslam Bhutta M.M., Hayat N., Bashir M.H., Khan A.R., Ahmad K.N., Khan S.: CFD applications in various heat exchangers design: A review. Journal "Applied Thermal Engineering", 32, 2012, pp. 1 - 12. ISSN 1359-4311.

[7] Prepiorka-Stepuk J., Jakubowski M.: Numerical studies of fluid flow in flat, narrow-gap channels simulating plate heat exchanger. Journal "Chemical and Process Engineering", 34, 2013, pp. 507 - 514. ISSN 2300-1925.

[8] Han X.-H., Cui L.-Q., Chen G.-M., Wang Q.: A numerical and experimental study of chevron, corrugated-plate heat exchangers. Journal "International Communications in Heat and Mass Transfer", 37, 2010, pp. 1008 - 1014. ISSN 0735-1933.

[9] Tsai Y.-C., Liu F.-B., Shen P.-T.: Investigations of the pressure drop and flow distribution in a chevron-type plate heat exchanger. Journal "International Communications in Heat and Mass Transfer", 36, 2009, pp. 574 - 578. ISSN 0735-1933.

[10] Freund S., Kabelac S.: Investigation of local heat transfer coefficients in plate heat exchangers with temperature oscillation IR thermography and CFD. International Journal of Heat and Mass Transfer, 53, 2010, pp. 3764 - 3781. ISSN 0017-9310.

[11] Pandey S.D., Nema V.K.: Analysis of Heat Transfer, Friction Factor and Exergy Loss in Plate Heat Exchanger Using Fluent. Journal "Energy and Power", 1, 2011, pp. 6 - 13. ISSN 2163-1603.
[12] Wang Y.-Q., Dong Q.W., Liu M.S., Wang D.: Numerical Study on Plate-Fin Heat Exchangers with Plain Fins and Serrated Fins at Low Reynolds Number. Journal "Chemical Engineering \& Technology", 32, 2009, pp. 1219 - 1226. ISSN 1521-4125.

[13] Grijspeerdt K., Hazarika B., Vucinic D.: Application of computational fluid dynamics to model the hydrodynamics of plate heat exchangers for milk processing. Journal of Food Engineering, 57, 2003, pp. 237 - 242. ISSN 0260-8774.

[14] Schlunder E.U.: Heat exchanger design handbook. International Centre for Heat and Mass Transfer, 1983, 2305 p. ISBN 3-1841-9081-1.

[15] Vedernikova M.I., Talankin V.S.: Calculation of plate heat exchangers. Methodological guidelines for course and diploma projects. Ural State Forest Engineering University. Yekaterinburg, 2008, 29 p.

[16] Mamchenko V.O., Malyshev A.A.: Plate heat exchangers in cryogenic techniques and biotechnological processes. Study guide. Saint Petersburg National Research University of Information Technologies, Mechanics and Optics. Institute of Refrigeration and Biotechnology. Saint Petersburg, 2014, 117 p.

[17] https ://grabcad.com [2015-08-01].

[18] ANSYS, Inc. ANSYS Meshing User's Guide. Release 15.0. 2013, 492 p.

[19] Vieser W., Esch T., Menter F.: Heat transfer predictions using advanced two-equation turbulence models. CFX Validation Report No. CFX-VAL10/060211, 2002, 73 p.

[20] Plankovskyy S.I., Shypul O.V., Tryfonov O.V., Palaziuk Ie.S., Malashenko V.L.: The simulation of the heat transfer during shock waves damping in an enclosed chamber. Journal "Aerospace equipment and technology", 1 (108), 2014, pp. 104 - 109. ISSN 1727-7337.

[21] ANSYS, Inc. ANSYS CFX-Pre User's Guide. Release 15.0. 2013, $386 \mathrm{p}$.

[22] ANSYS, Inc. ANSYS CFD-Post User's Guide. Release 15.0. 2013, 376 p. 